NEWS

\title{
Swine flu goes global
}

New influenza virus tests pandemic emergency preparedness.

Researchers are scrambling to study the evolution and spread of the novel H1N1 strain of swine influenza whose leap to humans was officially confirmed last week. The possible imminent onset of a swine-flu pandemic is also testing international preparedness plans put into place to deal with something else: the much-feared $\mathrm{H} 5 \mathrm{~N} 1$ avian flu virus that has spread across Asia, Europe and Africa since 2003.

The genetic make-up of this swine flu virus is unlike any that researchers have seen. It is an H1N1 strain that combines a triple assortment first identified in 1998 - including human, swine and avian influenza - with two new pig $\mathrm{H} 3 \mathrm{~N} 2$ virus genes from Eurasia, themselves of recent human origin.

"It has been mixing all over the place, and so the genetics are quite complicated," says John McCauley, a virologist at the UK Medical Research Council's National Institute for Medical Research in London. "Where the hell it got all these genes from we don't know," says Robert Webster, a flu virologist at St Jude Children's Research Hospital in Memphis, Tennessee. "But this is a real super-mixed-up virus."

As Nature went to press, more than 150 people were thought to have died from the virus in Mexico, with some 1,600 cases suspected there. At least 87 cases have been confirmed in other countries, including the United States, Canada, New Zealand, the United Kingdom, Spain and Israel.

On 27 April, the World Health Organization (WHO) raised its pandemic threat from phase 3 - a new flu virus infecting humans but with limited human-to-human spread - to phase 4 , with community outbreaks that mark "a significant upwards shift in the risk for a pandemic". The scale runs to 6: a full-blown pandemic.

\begin{abstract}
"The scary thing is that this virus seems enormously transmissible," says Webster. In New York, for instance, at least 28 students at a school in Queens have come down with it.

The US Centers for Disease Control and Prevention (CDC) and the WHO are trying to nail down how many of the reported deaths in Mexico are due to swine flu and how many are due to other causes. "The spectrum of illness is still a matter of doubt and conjecture," says David Ozonoff, an epidemiologist at the Boston University School of Public Health in Massachusetts. For instance, rumours swirled that archaeologist Felipe Solis, the director of the National Museum of Anthropology in Mexico City who had met recently with US President Barack Obama, died on 23 April as a result of the swine flu. Mexican authorities later reported he died of cardiac arrest linked to pneumonia.
\end{abstract}

\section{No human immunity}

The virus seems to have first taken hold in Mexico in mid-March; it was identified when Mexican authorities sent samples from a flu patient that it could not subtype to the Canadian Public Health Agency. After cases in California, the CDC announced the existence of the virus on 23 April.

The genetics of the virus are so novel that humans are unlikely to have much immunity to it, scientists say. The current seasonal flu vaccine, which targets a different H1N1 strain, also isn't likely to offer any protection. Discussions are under way as to whether a new vaccine for the swine flu strain should be produced. The WHO has recommended that vaccine makers continue to manufacture the seasonal flu strain but begin thinking about how to manufacture large doses of a vaccine that incorporates a weakened version of the

\section{RESEARCH QUESTIONS TO ANSWER}

Virulence, including mortality rate: how the disease progresses within infected individuals.

Transmission characteristics: how quickly it spreads among individuals.
Genetics: how the virus acquired its jumble of genetic snippets.

\section{Drug resistance: whether} the new strain will evolve to be untreatable by the two flu drugs that can treat it now.
Vaccines: how to obtain and characterize viral isolates and decide which antigens to include in a vaccine.

Prevention: how to limit spread and buy time until a vaccine is available.

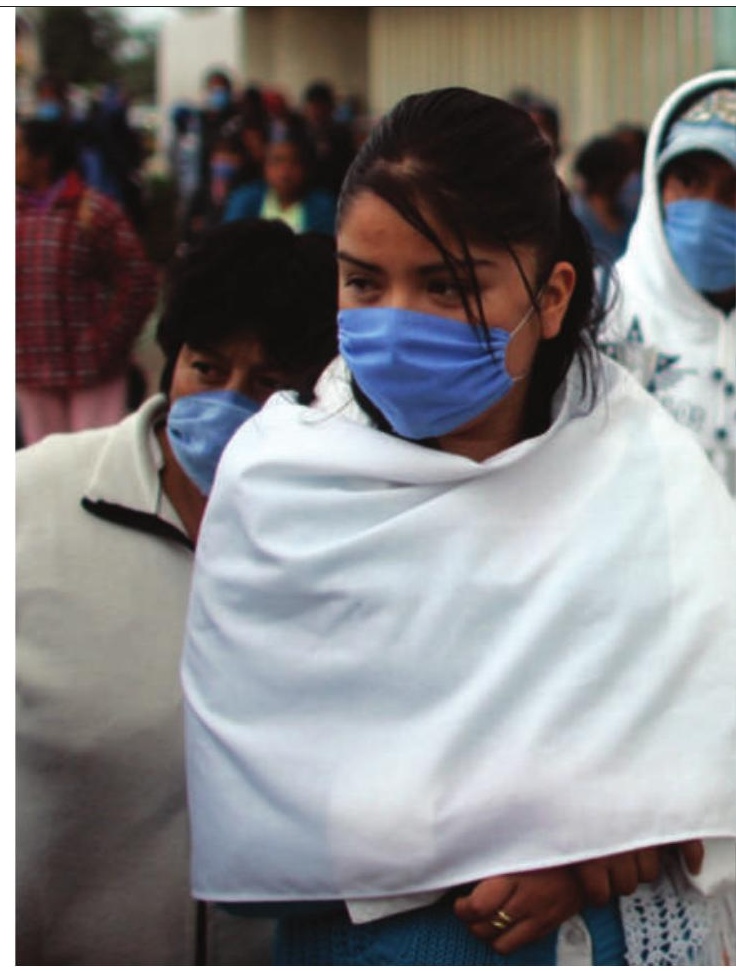

Face masks are being used - in Toluca, Mexico, and elsewhere - to try to stop the virus spreading.

current swine flu strain. For now, the virus is treatable with the influenza drugs oseltamivir (Tamiflu) and zanamivir (Relenza).

So far, cases in the United States and elsewhere seem to have been relatively mild compared with those in Mexico. Tashiro Masato, a virologist at the National Institute of Infectious Diseases in Tokyo, warns against drawing any conclusions from this. He notes that the sample of cases from the United States is too small to pick up even single-digit mortality rates. If transmission rates turn out to be high (see 'Research questions to answer'), mortality rates of even a few per cent could lead to millions of deaths, as in the pandemic of 1918.

For the moment the pathogenicity and mortality range is wide and uncertain, says $\mathrm{McCau}$ ley - "anything between the lethal 1918 and the mild 1968 pandemic". The high transmission rates in areas such as New York are worrying, says Mark Lipsitch, an epidemiologist of the Harvard School of Public Health in Boston, Massachusetts. But a better idea should be forthcoming as testing ramps up, and health authorities get a clearer picture of the ratio of deaths to those infected.

The new virus, however, comes nowhere near the mortality rates of $\mathrm{H} 5 \mathrm{~N} 1$, which have averaged around $63 \%$ globally and reached as high as $82 \%$ in Indonesia. "The risk and threat of $\mathrm{H} 5 \mathrm{~N} 1$ remain as before", Masato warns.

Epidemiologists are largely applauding the 


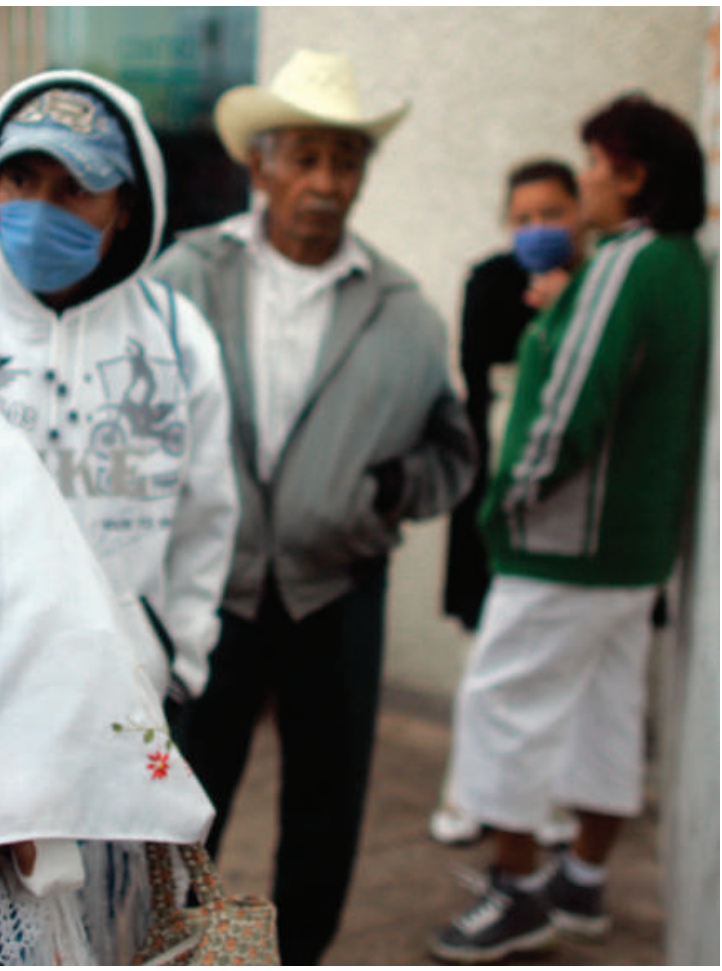

speed and scale of the response to the swine flu outbreak since it was formally identified last week, even though Mexican and international disease surveillance systems failed to pick it up promptly at the start. Several scientists speculate that the initial cases were months ago and perhaps outside Mexico. Ambitious WHO plans to quickly detect and extinguish an emerging pandemic before it grew, by distributing flu drugs, were thus not useful.

But once the virus was officially announced, governments have swung into action. The United States, for instance, has released onequarter of its 50 million stockpiled doses of oseltamivir and zanamivir for treatment in the affected states. The international response is being largely attributed to the amount of pandemic planning undertaken since the threat of a $\mathrm{H} 5 \mathrm{~N} 1$ pandemic emerged. Gene sequences of the virus samples, for instance, have been promptly shared on the Global Initiative on Sharing Avian Influenza Data (GISAID) database. Sequence information can have practical significance - for example, in designing PCR primers, to make rapid diagnosis tests that broaden and speed up surveillance.

Many virologists think they are in for the long haul. "Will this fizzle out? It doesn't look like it to me," says McCauley. "For me this is the time to start deploying national pandemic plans. We need to act now."

Declan Butler

For Nature's coverage of the swine flu outbreak, see www.nature.com/swineflu.

\section{California in clean-fuel drive}

The state of California has adopted regulations to curb greenhouse-gas emissions from transportation fuels, codifying evidence that biofuels are significantly dirtier than they were once thought to be.

The California Air Resources Board approved its 'low-carbon fuel standard' on 23 April, requiring fuel providers to cut the greenhouse-gas emissions from fuels by $10 \%$ by 2020 , compared with 2010 levels. The rule would also accomplish $10 \%$ of California's requirement to reduce emissions to 1990 levels by 2020, part of a broader plan to cut emissions by $80 \%$ by mid-century.

"We really think this is the future of fuels policy globally," says Anthony Eggert, a science adviser to the board. He says the policy should send a signal to the private sector and "drive clean transportation fuels and infrastructure into the market".

The regulation includes greenhousegas-emissions calculations for the life cycle of all fuels. To meet the requirement, refiners and importers would have to improve their production methods or mix and match the fuels that they sell. If they beat the standard, they can sell credits for their unused emissions to someone else.

Despite intense opposition from the US corn (maize) ethanol industry, the rule takes into account agricultural expansion abroad caused by rising grain prices as food crops are diverted for biofuels. This 'indirect' effect boosts the estimated emissions for various categories of corn ethanol by $50 \%$ or more, meaning that ethanol often results in higher greenhouse-gas emissions than gasoline.

Matt Hartwig, a spokesman for the Renewable Fuels Association in Washington DC, questions the science behind indirect emissions and says California has vastly overstated the problem. Many researchers, however, think there is enough evidence to move forwards now and re-evaluate as the science improves.

Dan Kammen, an energy researcher at the University of California, Berkeley, says California's calculation for indirect emissions is "reasonably consistent" with his team's work. "The science is new and evolving," he says, "but the low-carbon fuel standard is exactly the right approach."

The US Environmental Protection Agency is reviewing its own ruling that will establish greenhouse-gas criteria under the national biofuels mandate. European regulators are also looking into indirect emissions, but are not expected to make a determination until next year.

Tim Searchinger, an environmental researcher at Princeton University in New Jersey, identified the indirect effect in 2008 (T. Searchinger et al. Science 319, 1238-1240; 2008). He says California was conservative in its calculation of indirect emissions. His work suggests that corn ethanol could double emissions compared with gasoline over 30 years.

But one of the reasons for this difference, he says, is because California assumes that half of the food crops that are redirected towards energy will not be replaced because of rising prices, which he says translates into hunger in poorer countries. "Even though it's a best-case scenario for corn ethanol, the impact is still significant," Searchinger says. "Corn ethanol basically has no benefit, and it causes hunger."

Brazilian sugarcane ethanol, despite having an even higher indirect effect and being transported abroad, still performs better than any other biofuel. The California regulation does not yet include specific numbers for biodiesel, although the indirect impact could be even higher because of massive
expanding palm-oil emissions from expanding palm-oil
plantations, particularly in Indonesia. plantations, particularly in Indonesia.
The California regulation also covers fuels produced from the Canadian tar sands, which produce more emissions than conventional oil because of the energyintensive extraction process. The lowcarbon fuel standard could also prove a barrier to coal-based fuels, while providing a boost to vehicles powered by natural gas and electricity. Jeff Tollefson 